\title{
A comparative study of the incorporation of a $1,6-\beta$-glucan and an 0 -glycosylated protein epitope into the cell wall of Candida albicans
}

\author{
Raquel Sanjuán, Jesús Zueco, Jacqueline Pérez, Carlos Peñarroja \\ and Rafael Sentandreu
}

Departament de

Microbiologia, Facultat de Farmàcia, Universitat de València, Avgda. Vicent Andrés Estellés $s / n, 46100$ Burjassot (València), Spain

\author{
Author for correspondence: Rafael Sentandreu. Tel: + 346 3864299. Fax: +3463864682. \\ e-mail : rafael.sentandreu(a uv.es
}

\begin{abstract}
The topological distribution of two epitopes in the cell wall of Candida albicans, the kinetics of their incorporation into the regenerating protoplast wall, and the effect of different antibiotics upon their incorporation and localization have been studied. To do so, two monoclonal antibodies that react against an 0 -glycosylated mannoprotein (1B12) and against a 1,6- $\beta$-glucan epitope (JRR1) were used. The results show that the JRR1 epitope is localized in an internal layer of the cell wall, in contrast to the 1 B12 epitope, which is superficial, and that the incorporation of the JRR1 epitope into walls of regenerating protoplasts precedes that of the 1B12 epitope. The JRR1 epitope is normally found in the culture medium of control cells, but not in that of papulacandin-B-treated cells, and tunicamycin interferes with the incorporation of the 1 B12 epitope into the cell walls. Finally, the results support the hypothesis that mannoproteins are not 1,6- $\beta$-glycosylated before their secretion.
\end{abstract}

Keywords: Candida albicans cell wall, monoclonal antibodies, epitope incorporation and assembly

\section{INTRODUCTION}

Candida albicans is a dimorphic fungus that grows either as an ellipsoidal budding yeast or as a pseudomycelial organism, depending on the environmental conditions; true mycelial cells can, in some cases, also be seen. $C$. albicans is one of the most pervasive of the pathogenic fungi, especially infecting immunocompromised hosts, in which it can invade various tissues (Bodey, 1984; Odds, 1988).

The cell wall is the structure responsible for the characteristic shape of each cellular form, and it is also the site of initial interaction between the organism and the host. Consequently, information about the wall components and their organization is important in our understanding of their role in cell integrity and host-parasite interactions.

The cell wall of $C$. albicans is mainly composed of $\beta$ glucans and mannoproteins, together with a small but significant amount of chitin (Chattaway et al., 1968;

Abbreviation: IIF, indirect immunofluorescence.
Sullivan et al., 1983; Sentandreu et al., 1994). The three components are dispersed throughout the cell wall, although the mannoproteins are mostly concentrated on the outer surface (Elorza et al., 1989; Calderone \& Braun, 1991 ; Shepherd \& Gopal, 1993). Some of the wall proteins are released by hot SDS and the remaining ones are released in the form of supramolecular, highly polydisperse complexes after the degradation of the structural skeleton by $\beta$-glucanases and chitinase (Ponton \& Jones, 1986; Elorza et al., 1988, 1989; Marcilla et al., 1991, 1993). Recently, Kapteyn et al. (1994) and Sanjuán et al. (1995) have reported that $1,6-\beta$-glucan is linked to mannoproteins in C. albicans. According to Kapteyn et al. (1994, 1995a), this linkage, and the linkage between mannoproteins and 1,3- $\beta$-glucan, would be of the phosphodiester type. Information about the native cell-wall proteins has been gained by analysing the materials secreted by regenerating protoplasts using polyclonal and monoclonal antibodies (mAbs) as specific probes (Elorza $e t$ al., 1994 ; Kapteyn et al., 1995b).

In the present article, we extend previous observations and report the use of two mAbs, one (1B12) which is specific for an epitope present in an O-glycosylated 
mannoprotein (Marcilla et al., 1993; Mormeneo et al., 1994), and the other (JRR1) which reacts against a 1,6- $\beta$ glucosyl residue (Sanjuán et al., 1995). Both have been used to determine the topological location of the corresponding antigens in the walls, and how their assembly in the cell wall is affected by different antibiotics. In addition, the kinetics of incorporation of these antigens in the regenerating walls of protoplasts have also been studied. The results obtained demonstrate that the first antigen, the $O$-glycosylated protein, is connected directly or indirectly to the glucan, mannoproteins and chitin of the wall. In addition, it is located on the outer surface of the wall. The second epitope is found below the cell surface in veast cells and partially exposed in mycelial cells. Our aim in studying these two specific antigens was to extrapolate our findings to the process of secretion and incorporation of $1,6-\beta$-glucan and $O$-glycoproteins into the cell wall of $C$. albicans.

\section{METHODS}

Strains and conditions of growth. Candida albicans ATCC 26555 serotype A was grown according to Elorza et al. (1989). Cells incubated at $28^{\circ} \mathrm{C}$ in Lee's medium (Lee $e t$ al., 1975) were collected after $12-18 \mathrm{~h}$, when they were at their exponential growth phase. For the formation of mycelium, yeast cells stored in water at $4{ }^{\circ} \mathrm{C}$ for $24-42 \mathrm{~h}$ were incubated at $37^{\circ} \mathrm{C}$ for $6 \mathrm{~h}$ in Lee's medium and then collected. To analyse the effect of tunicamycin, papulacandin B and nikkomycin $Z$ on the incorporation of the mAb JRR1 and $1 \mathrm{~B} 12$ epitopes in the cell walls, yeast cells kept in water at $4{ }^{\circ} \mathrm{C}$ for $48-72 \mathrm{~h}$ were incubated in Lee's medium at 28 and $37^{\circ} \mathrm{C}$ for $2 \mathrm{~h}$. The antibiotics were added at a final concentration of $20 \mu \mathrm{g} \mathrm{m}^{-1}$, $2.5 \mu \mathrm{g} \mathrm{ml} l^{-1}$ and $50 \mu \mathrm{g} \mathrm{ml}^{-1}$, respectively. After $4 \mathrm{~h}$ incubation, the cells and medium were separated by centrifugation, and the medium was exhaustively dialysed against distilled water, concentrated $\times 20$ by lyophilization and used to coat ELISA plates.

Preparation of protoplasts, regeneration conditions and preparation of the regenerating walls. Protoplasts from $C$. albicans were obtained as previously described by Murgui $e t$ al. (1986) and regenerated at $28^{\circ} \mathrm{C}$ in Lee's medium supplemented with $0.6 \mathrm{M} \mathrm{KCl}$ as an osmotic stabilizer. After different periods of time, medium was separated from protoplasts by centrifugation, dialysed and concentrated by lyophilization. One microgram of protein, as measured by the Lowry method, was used to coat ELISA wells.

Regenerating walls were obtained as follows: first, water was added to the protoplasts to cause their osmotic lysis and then the walls were separated from the rest of the cell by centrifugation. The cell walls of regenerating protoplasts obtained after 4, 8 and $24 \mathrm{~h}$ regeneration time were obtained as described for cell walls of growing cells (Marcilla et al., 1993).

Analysis of the spent medium and cell-wall material. The spent medium was analysed by ELISA as described by Sanjuán et al. (1995). Cell-wall material was solubilized by Zymolyase $20 \mathrm{~T}$ according to Marcilla et al. (1993) and analysed by ELISA in plates coated with $5 \mu \mathrm{g}$ sugar as determined by the method of Dubois et al. (1956). mAbs JRR1 and 1B12 were used
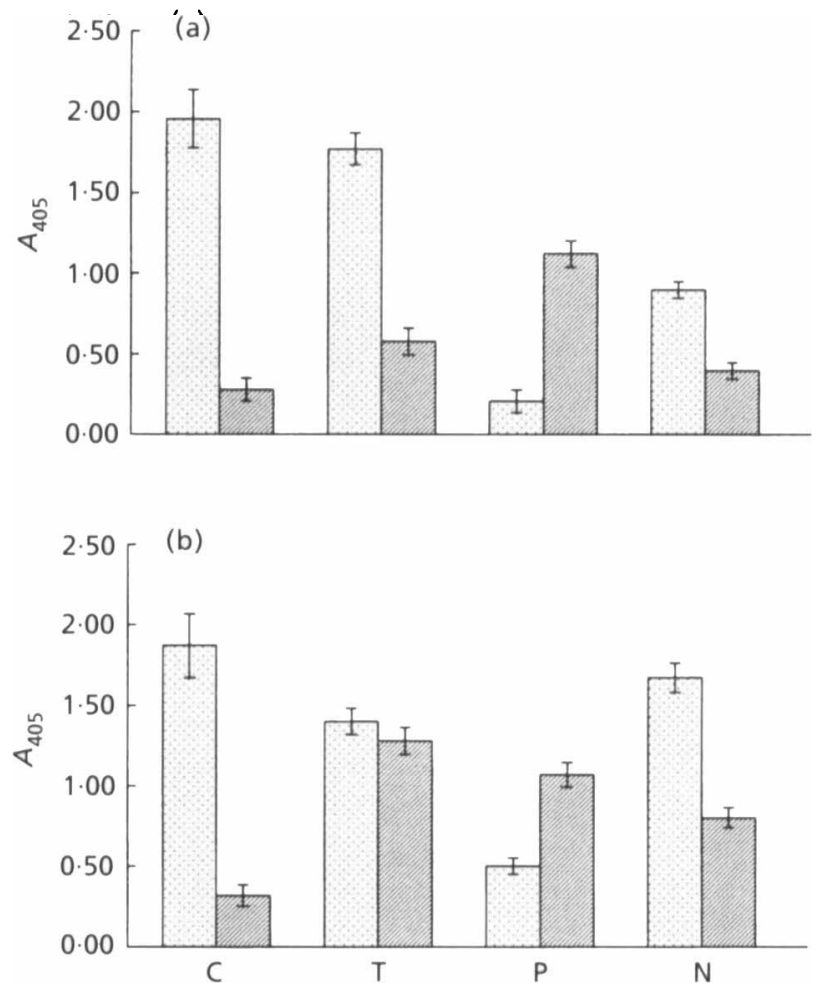

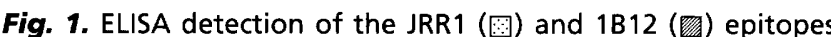
present in the culture medium of $C$. albicans cells grown in the absence $(C$, control) or in the presence of antibiotics $(T$, tunicamycin; P, papulacandin B; N, nikkomycin Z). Wells were coated in triplicate with the same volume of each dialysed and concentrated medium. (a) Yeast; (b) mycelium.

for ELISA at a final concentration of $1: 1000$ and 1:8000, respectively.

ELISA. These assays were performed as described previously by Voller \& Bidwell (1986) with the following modifications. Nunc-Immunoplate I (A/S Nunc) plates were coated with the appropriate amounts of different materials and incubated overnight at $4{ }^{\circ} \mathrm{C}$. The wells were rinsed three times with Trisbuffered saline (TBS) $/ 0.05 \%(\mathrm{v} / \mathrm{v})$ Tween 20 (TBST) then filled with $3 \%(\mathrm{w} / \mathrm{v})$ bovine serum albumin in TBS and incubated for $2 \mathrm{~h}$ at $37^{\circ} \mathrm{C}$. Each plate was washed three times with TBST. The appropriate diluted antibody $(1: 1000$ for $\mathrm{mAb}$ JRR1 and $1: 8000$ for 1B12) in TBST was added to the wells and the plate was incubated at $37^{\circ} \mathrm{C}$ for $2 \mathrm{~h}$. After washing three times with TBST, an alkaline-phosphatase-conjugated goat anti-mouse immunoglobulin (Bio-Rad) was diluted 1:500 in TBST and $50 \mu \mathrm{l}$ was added to the wells. After $2 \mathrm{~h}$ at $37^{\circ} \mathrm{C}$, the wells were rinsed again and the substrate mixture $(50 \mu l$ $p$-nitrophenylphosphate, $1 \mathrm{mg} \mathrm{ml}^{-1}$, in diethanolamine buffer) was added to each well and developed for $45 \mathrm{~min}$. The colour intensity was read at $405 \mathrm{~nm}$ with a plate reader (Titertek Multiscan Plus MKII; Labsystems).

Indirect immunofluorescence (IIF) for detection of cellsurface antigens. The immunofluorescence assay was carried out as described by Sanjuán et al. (1995). Cells growing in the

Fig. 2. Analysis by immunofluorescence of the distribution of the JRR1 epitope on the surface of $C$. albicans yeast (a, b) and mycelial $(c, d)$ cells and the effect of tunicamycin $(e-h)$ on the incorporation of the epitopes into the cell wall. (a, $c$, e, g) Phase-contrast micrographs; (b, $d, f, h)$ fluorescence micrographs. Arrows point to fluorescent surfaces in $(e)-(h)$. 

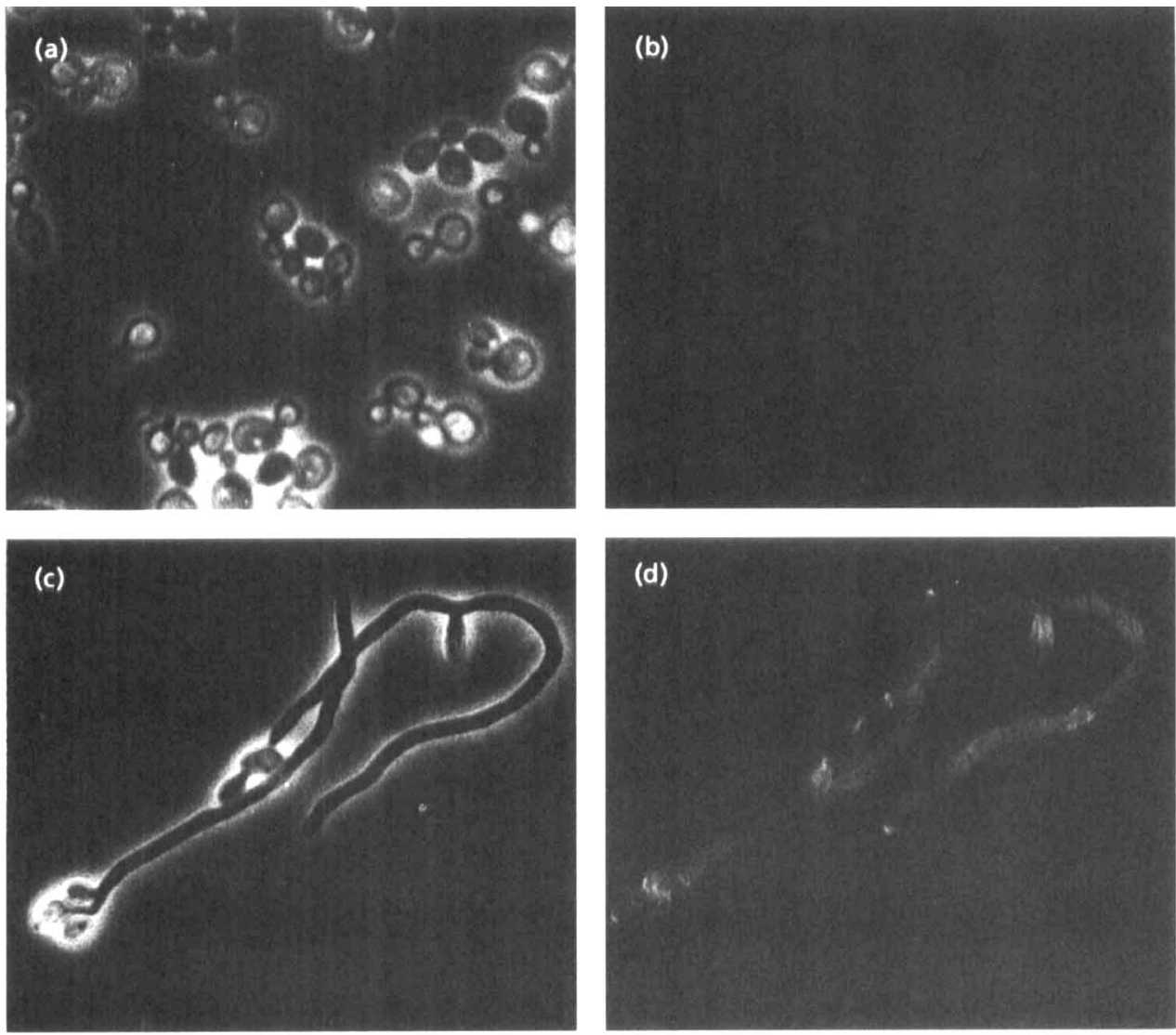

(d)
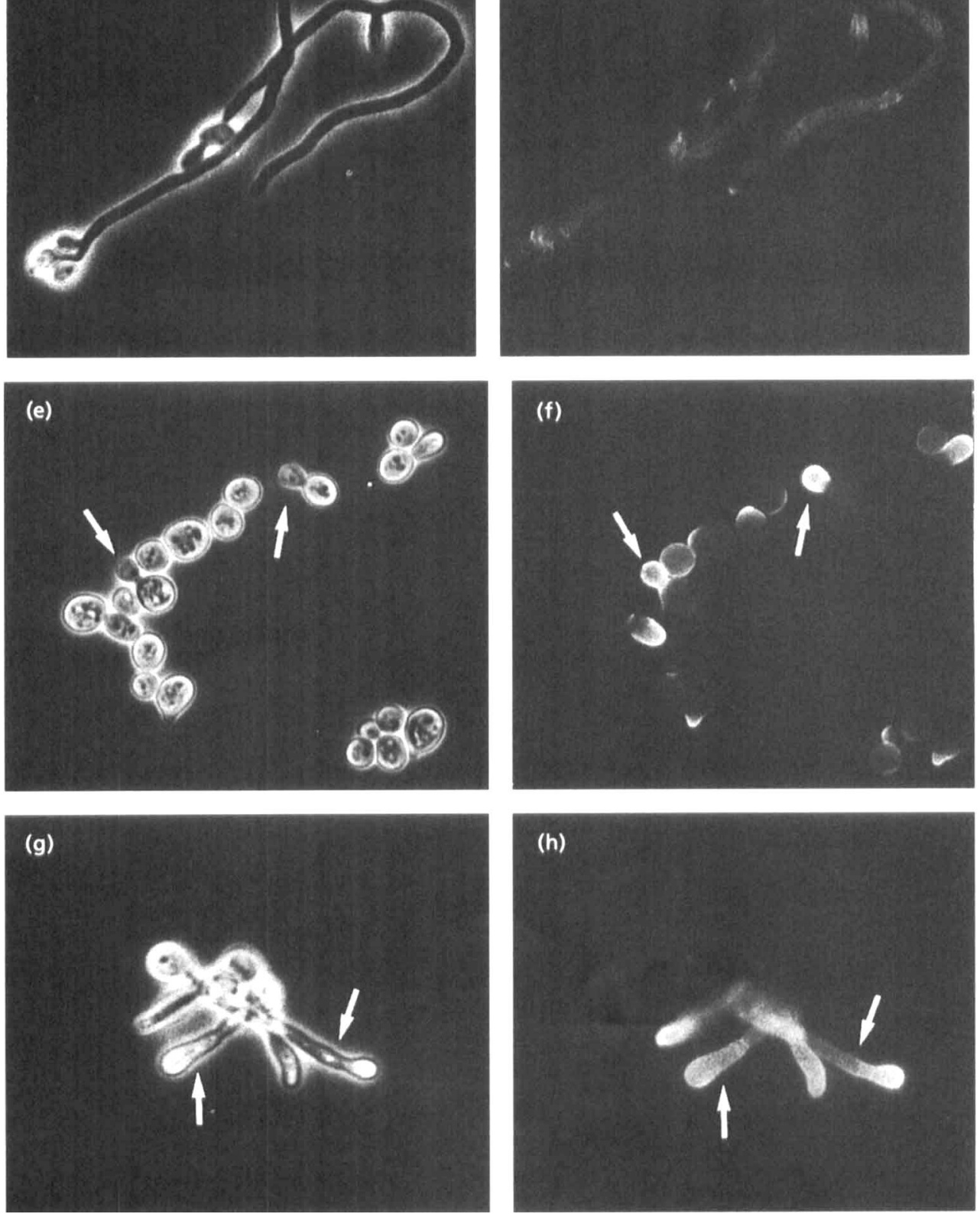

(h)

Fig. 2. For legend see facing page. 

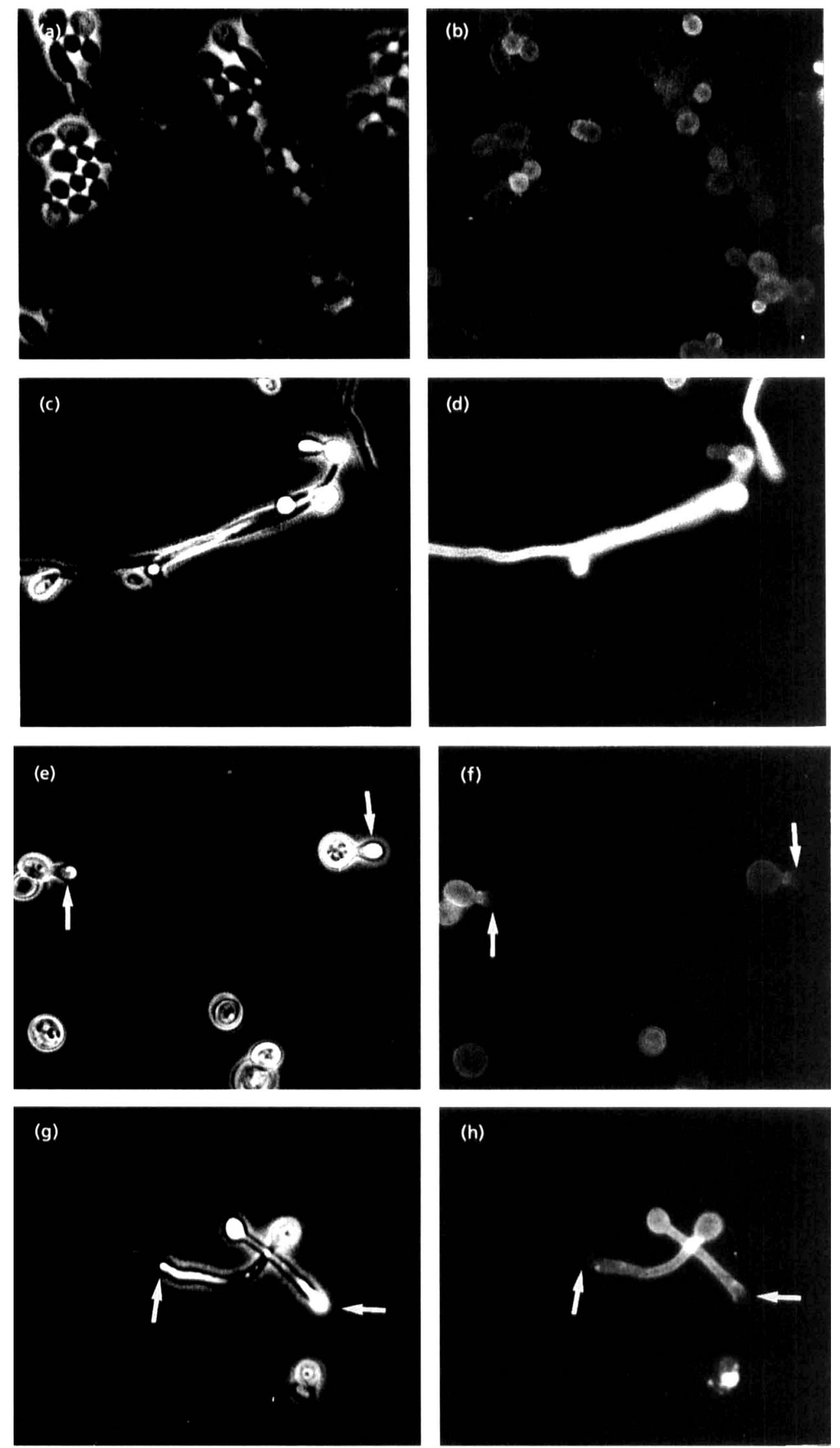

Fig. 3. For legend see facing page. 
presence or absence of antibiotics were not fixed before performing the IIF. Protoplasts were fixed for $45 \mathrm{~min}$ in $2 \%$ $(\mathrm{v} / \mathrm{v})$ formaldehyde solution containing $0.6 \mathrm{M} \mathrm{KCl}$ as an osmotic stabilizer. Unfixed cells or fixed protoplasts were washed three times with PBS $(0 \cdot 145 \mathrm{M} \mathrm{NaCl} ; 0 \cdot 15 \mathrm{M}$ sodium phosphate) and incubated at $37^{\circ} \mathrm{C}$ for $1 \mathrm{~h}$ with the appropriate dilution in PBS of the antibody $(1: 25$ for $\mathrm{mAb}$ JRR $1 ; 1: 50$ for 1B12). After three washes with PBS, the cells were incubated with fluorescein-isothiocyanate-conjugated goat anti-mouse $\operatorname{IgG}$ (Boehringer Mannheim), diluted 1:10 in PBS, at $37^{\circ} \mathrm{C}$ for $1 \mathrm{~h}$. After three washes with PBS, the cells were examined with a Zeiss Photo Microscope III equipped for epifluorescence. Fluorescence was dependent on the reaction of the cells with the $\mathrm{mAbs}$, since no fluorescence was detected when the cells were incubated with the second antibody only.

\section{RESULTS}

\section{Effect of different antibiotics on the release of JRR1 and 1B12 antigens into the medium of growing cells}

Antibiotics inhibiting $N$-glycosylation of proteins (tunicamycin) or formation of glucan (papulacandin B) or chitin (nikkomycin Z) were added to the medium of growing cells in an attempt to obtain information on the role of the different macromolecules in the structure of the cell wall. The supernatant of the spent medium was collected and the presence of the antigens reacting with mAbs JRR1 and $1 \mathrm{~B} 12$ was assayed by ELISA.

The JRR1 epitope was detectable in the spent medium of cells grown at either 28 or $37^{\circ} \mathrm{C}$ in the absence of antibiotics, as well as in the presence of tunicamycin and nikkomycin, but not in the spent medium of cells grown in the presence of papulacandin B (Fig. 1).

The antigen 1B12 was not found in the supernatant of control yeast cells, but significant amounts were detected in the spent medium of cells grown in the presence of tunicamycin and nikkomycin and in even greater amounts in the spent medium of cells grown in the presence of papulacandin B (Fig. 1a). In mycelial cells, the results were similar, although tunicamycin seemed to inhibit most of the incorporation of the 1B12 antigen into the cell wall (Fig. 1b).

\section{JRR1 and 1B12 antigens have different locations in the cell wall}

To determine the distribution of these antigens in yeast and mycelial $C$. albicans cell walls, IIF assays were carried out with the corresponding mAbs. The behaviour of $\mathrm{mAb}$ JRR1 differed depending on the morphology of the cells; it did not label the surface of the yeast form, whereas mycelial cells were lightly stained (Fig. 2a-d). Nevertheless, the areas of the wall synthesized during the period of incubation in the presence of tunicamycin (the buds in the yeast form and the tips of mycelial cells) were brightly labelled (Fig. 2e--h). These results indicate that the epitope lies in the inner part of the cell wall, which becomes

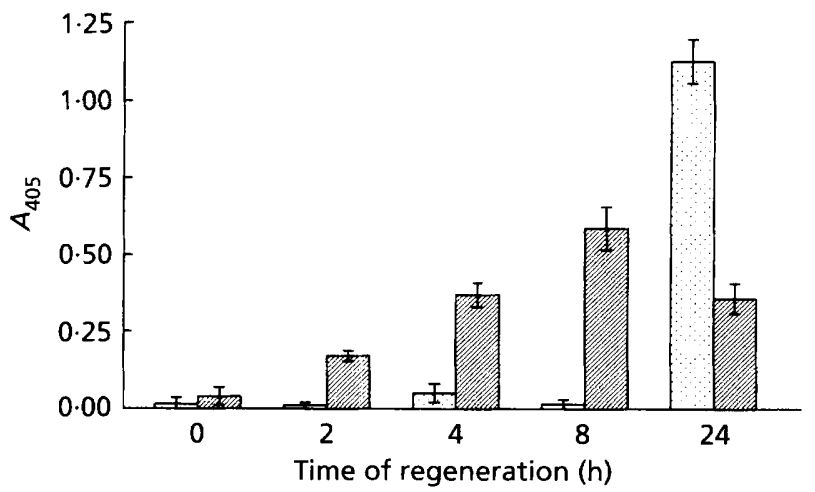

Fig. 4. Analysis by ELISA of the secretion of the JRR1 (圆) and $1 \mathrm{~B} 12$ (洫) antigens into the medium of regenerating protoplasts incubated for $2,4,8$ and $24 \mathrm{~h}$ at $28^{\circ} \mathrm{C}$. The ELISA wells were coated with $1 \mu \mathrm{g}$ (valued as protein) of dialysed and concentrated medium.

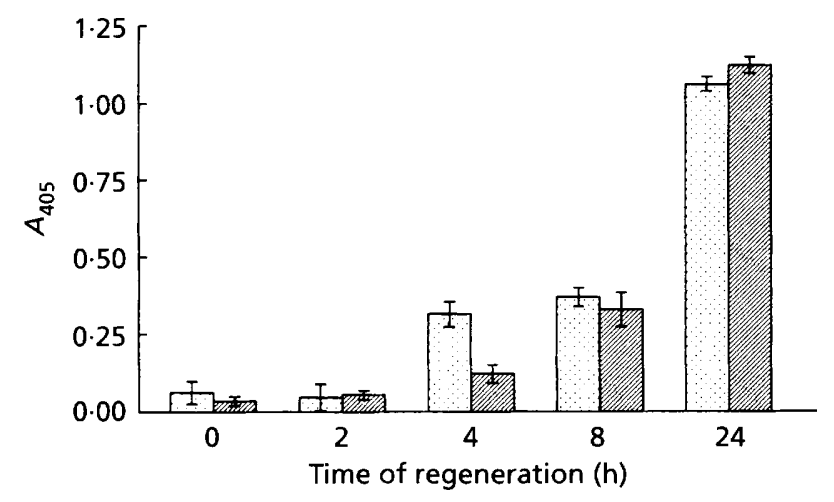

Fig. 5. ELISA determination of the JRR1 () and $1 B 12$ (畹) antigens in the material solubilized by Zymolyase from isolated 'walls' of protoplasts at different times of regeneration at $28^{\circ} \mathrm{C}$. Zymolyase-extracted material $(5 \mu \mathrm{g}$, valued as sugar) was used to coat the wells.

accessible to the antibody only when the outer layer of mannoproteins is disturbed by the effect of tunicamycin on $N$-glycosylation.

The experiments were also performed with $\mathrm{mAb} 1 \mathrm{~B} 12$. This antibody uniformly stained the surface of both yeast and mycelial cells grown in the absence of tunicamycin (Fig. 3a-d). However, this staining pattern changed noticeably in the case of the cell surfaces that had been synthesized in the presence of the antibiotic in that the buds and the apical part of the mycelial cells were not labelled by the antibody (Fig. 3e-h). This result is compatible with the detection by Western blotting of the $1 \mathrm{~B} 12$ epitope in the spent medium of tunicamycin-treated cells (data not shown).

Fig. 3. Analysis by immunofluorescence of the distribution of the $1 \mathrm{~B} 12$ epitope on the surface of $C$. albicans yeast (a, b) and mycelial $(c, d)$ cells and the effect of tunicamycin $(e-h)$ on the incorporation of the epitopes into the cell wall. (a, $c$, e, g) Phase-contrast micrographs; (b, $d, f, h$ ) fluorescence micrographs. Arrows point to non-fluorescent surfaces in (e)-(h). 

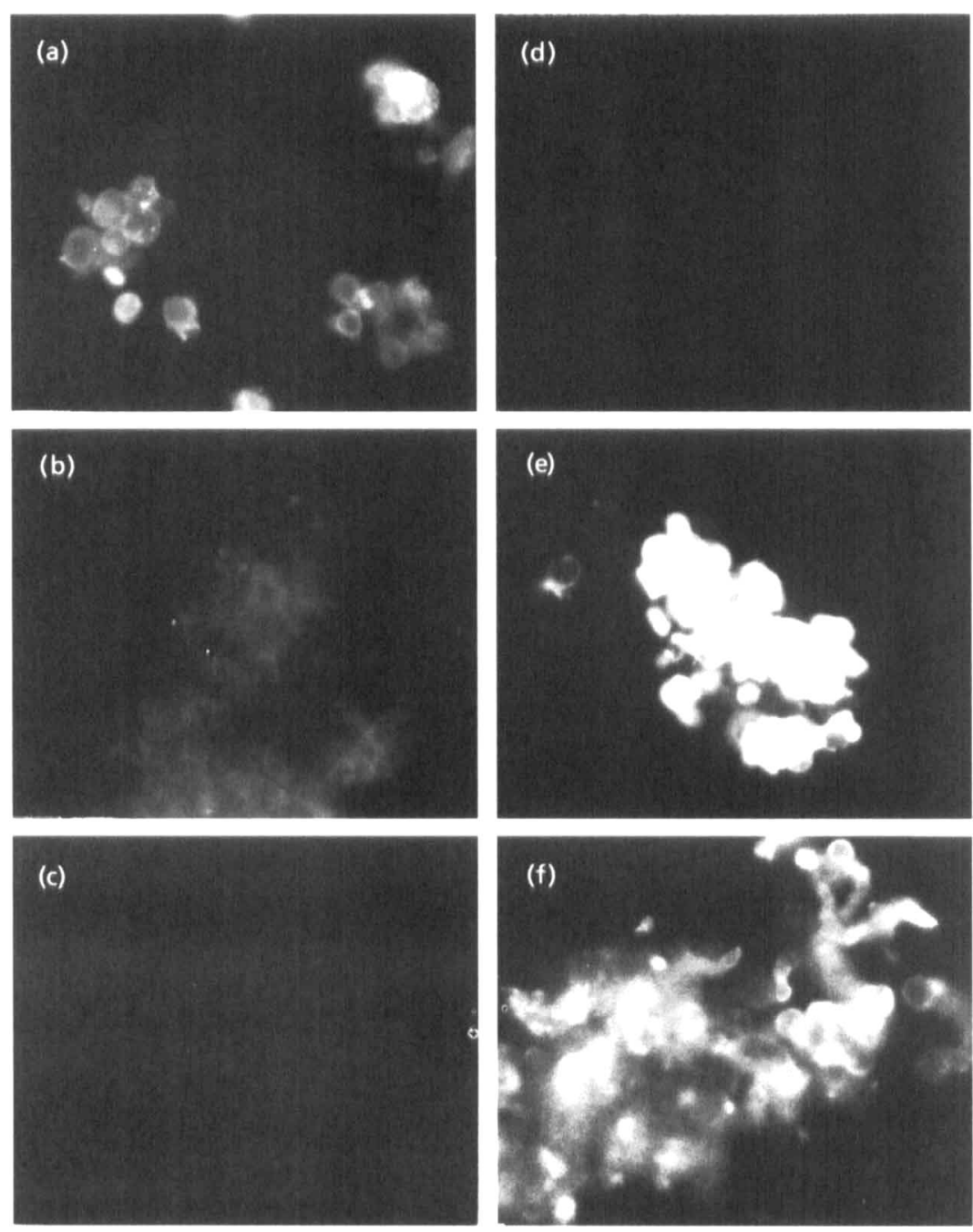

Fig. 6. Analysis by immunofluorescence of the incorporation and location of the JRR1 and $1 \mathrm{~B} 12$ antigens in the protoplast surfaces after $3(\mathrm{a}, \mathrm{d}), 5 \quad(\mathrm{~b}, \mathrm{e})$ and $7 \quad(\mathrm{c}, \mathrm{f}) \mathrm{h}$ regeneration. $(a, b, c)$ mAb JRR 1 ; (d, e, f) $\mathrm{mAb} 1 \mathrm{~B} 12$. Only fluorescence micrographs are shown.

\section{JRR1 and 1B12 antigens represent different models for the secretion and incorporation process in the regenerating protoplast walls}

In an attempt to clarify the secretion and incorporation pattern of the two antigens under study, we used regenerating protoplasts as a model. The regeneration process was followed by taking samples at $0,2,4$ and $8 \mathrm{~h}$ regeneration time and analysing the regeneration medium by ELISA and the regenerating walls by extraction with Zymolyase followed by ELISA of the extracts.

The ELISA analysis showed that the amount of $1 \mathrm{~B} 12$ epitope secreted into the medium increased with time (Fig. 4), probably due to the incapacity of the regenerating walls to retain mannoproteins. However, the JRR1 antigen was not found in the medium, at least during the first $8 \mathrm{~h}$, strongly suggesting that the JRR1 epitope is not bound to the mannoproteins secreted into the medium by regenerating protoplasts.

To study the kinetics of incorporation of both antigens, the protoplast 'walls', isolated at different times of regeneration, were treated with Zymolyase and the solubilized material was analysed by ELISA. As can be seen in Fig. 5, the first of the two epitopes to be incorporated into the regenerating wall was JRR1, as could be expected of an epitope that forms part of the glucan fibrillar network. Only after $4 \mathrm{~h}$, when the walls acquired some degree of structure, was the 1B12 epitope detected in appreciable amounts.

The incorporation of both epitopes into the surface of the protoplasts was also studied by IIF. The JRR1 epitope appears only after $3 \mathrm{~h}$ regeneration, and fades with time as the outer mannoprotein layer becomes retained by the glucan fibrillar network (Fig. 6a, b, c). The IIF pattern for the $1 \mathrm{~B} 12$ epitope is the opposite, appearing only after $5 \mathrm{~h}$ (Fig. 6d, e, f), as can be expected from a mannoprotein that itself forms part of the outer mannoprotein layer.

\section{DISCUSSION}

The two antibodies used in this study were chosen because of the very different nature of the epitopes recognized, a 1,6- $\beta$-glucan (JRR1) and an O-glycosylated mannoprotein (1B12). The primary reason for choosing these epitopes was that we expected them to be localized in different layers within the cell-wall structure. The 
accepted model for the cell wall of $C$. albicans consists of an inner layer of fibrillar material that includes glucan and chitin, together with some mannoproteins and an outer amorphous mannoprotein layer (Horisberger \& Vonlanthen, 1977; Koch \& Rademacher, 1980; Zlotnik et al., 1984).

Our results confirm this model and show the relative impermeability of the outer layer, which prevents the labelling of yeast cells with the JRR1 antibody. The labelling of the mycelial cells with the same antibody points to an increased permeability of this outer mannoprotein layer, probably reflecting the decreased thickness of the mycelial walls (Marcilla et al., 1991). Our results also show the importance of the $N$-glycosidic chains (inhibited by tunicamycin) in maintaining the integrity of the outer mannoprotein layer and suggest a role for these side-chains in anchoring the $1 \mathrm{~B} 12$ antigen to the inner fibrillar layer. Results of the IIF and the ELISA of the supernatant of tunicamycin-treated cells, using the two antibodies, confirm that tunicamycin interferes with the retention of the 1B12 epitope; as a consequence of the tunicamycin effect, the removal of a protein that forms part of the outer layer increases the accessibility of the JRR1 antibody to the inner one. A possible explanation for the fact that tunicamycin prevents the retention of the mannoprotein carrying the $1 \mathrm{~B} 12$ epitope, which is only $\mathrm{O}$ glycosylated (Marcilla et al., 1993; Mormeneo et al., 1994), would be that it is bound to the glucan network through an intermediate $N$-glycosylated mannoprotein. Finally, the 1,6- $\beta$-epitope was easily detectable by ELISA in the supernatant of control cells and fully regenerated protoplasts. The presence of this epitope could be explained by the existence of degradation fragments, products of the $\beta$-glucanase activities described in $C$. albicans (Notario, 1982). It is also noteworthy that the only antibiotic that drastically reduced the levels of the JRR1 epitope in the supernatant of cells was papulacandin B, an antibiotic that prevents the formation of glucan (Traxler et al., 1980; Debono \& Gordee, 1994; Font de Mora et al., 1993). This permits us to speculate on the use of the levels of this epitope in the culture medium as a rapid test to screen for new inhibitors of glucan synthesis.

The results of the experiments performed with the regenerating protoplasts are compatible with those discussed above, but also provide an insight into the way the structure of the cell wall is formed de novo. The combination of the IIF of the regenerating protoplasts and the ELISA of both the medium and the Zymolyase extracts of the regenerating walls shows that the deposition of the JRR1 epitope precedes that of 1B12. Consequently, the $1 \mathrm{~B} 12$ epitope is lost into the medium until the inner fibrillar layer, consisting partly of the JRR1 epitope, reaches a minimum structure. The IIF confirms this view, in that the JRR1 epitope became detectable only after $3 \mathrm{~h}$, while disappearing from the surface as the outer layer of mannoproteins, of which the 1B12 epitope forms a part, covers it.

One of the questions that has been raised recently concerns the site of glucosylation of cell-wall proteins. In Sac- charomyces cerevisiae, the synthesis of 1,6- $\beta$-glucan begins intracellularly (Meaden $e t$ al., 1990; Roemer et al., 1993); hence it is possible that some wall proteins are glucosylated intracellularly. In this context, Kapteyn et al. (1995b) provided evidence that $1,6-\beta$-glucosylation takes place extracellularly, based on the absence of $1,6-\beta$ glucosylated proteins in the supernatant of regenerating protoplasts. Our own results show that no 1,6- $\beta$-glucan epitope could be detected by ELISA in the supernatant of regenerating protoplasts, thus confirming the results of Kapteyn et al. (1995b), but the possibility cannot be excluded that this antigen is synthesized bound to a protein acceptor, which somehow remains bound to the plasma membrane until a minimum wall structure has been synthesized.

\section{ACKNOWLEDGEMENTS}

We thank Dr Hortensia Rico for her help with immunofluorescence. Raquel Sanjuán was supported by a grant from the Conselleria de Educació i Ciència de la Generalitat Valenciana. This work was partially supported by grants from the Ministerio de Educación y Ciencia, Dirección General de Investigación Científica y Técnica (PB93-0051) and the Ministerio de Sanidad y Consumo, Fondo de Investigaciones Sanitarias de la Seguridad Social $(95 / 1602)$.

\section{REFERENCES}

Bodey, G. P. (1984). Candidiasis: a growing concern. Am J Med 77, 1-48.

Calderone, R. A. \& Braun, P. C. (1991). Adherence and receptor relationships of Candida albicans. Microbiol Rev 55, 1-20.

Chattaway, F. W., Holmes, M. R. \& Barlow, A. J. E. (1968). Cell wall composition of the mycelial and blastospore forms of Candida albicans. J Gen Microbiol 51, 367-376.

Debono, M. \& Gordee, R. S. (1994). Antibiotics that inhibit fungal cell wall development. Annu Rev Microbiol 48, 471-497.

Dubois, M., Gilles, K. A., Hamilton, J. K., Rebes, P. A. \& Smith, F. (1956). Colorimetric method for determination of sugars and related substances. Anal Chem 28, 350-356.

Elorza, M. V., Marcilla, A. \& Sentandreu, R. (1988). Wall mannoproteins of the yeast and mycelial cells of Candida albicans: nature of glycosidic bonds and the polydispersity of their mannan moieties. $J$ Gen Microbiol 134, 2393-2403.

Elorza, M. V., Mormeneo, S., García de la Cruz, F., Gimeno, C. \& Sentandreu, R. (1989). Evidence for the formation of covalent bonds between macromolecules in the domain of the walls of Candida albicans mycelial cells. Biocbem Biophys Res Commun 162, 1118-1121.

Elorza, M. V., Marcilla, A., Sanjuán, R., Mormeneo, S. \& Sentandreu, R. (1994). Incorporation of specific wall proteins during yeast and mycelial protoplast regeneration in Candida albicans. Arch Microbiol 161, 145-151.

Font de Mora, J., Herrero, E. \& Sentandreu, R. (1993). A kinetic study on the regeneration of Candida albicans protoplasts in the presence of cell wall synthesis inhibitors. FEMS Microbiol Lett 111, 43-48. 
Horisberger, M. \& Vonlanthen, M. (1977). Location of mannan and chitin on thin sections of budding yeasts with gold markers. Arch Microbiol 115, 1-7.

Kapteyn, J. C., Montijn, R. C., Dijkgraaf, G. J.P. \& Klis, F. M. (1994). Identification of $\beta$-1,6-glucosylated cell wall proteins in yeast and hyphal forms of Candida albicans. Eur J Cell Biol 65, 402-407.

Kapteyn, J. C., Montijn, R. C., Dijkgraaf, G. J. P., Van den Ende, H. \& Klis, F. M. (1995a). Covalent association of $\beta-1,3$-glucan with $\beta-1,6$-glucosylated mannoproteins in cell walls of Candida albicans. $J$ Bacteriol 177, 3788-3792.

Kapteyn, J. C., Dijkgraaf, G. J.P., Montijn, R. C. \& Klis, F. M. (1995b). Glucosylation of cell wall proteins in regenerating spheroplasts of Candida albicans. FEMS Microbiol Lett 128, 271-277.

Koch, Y. \& Rademacher, K. H. (1980). Chemical and enzymatic changes in the cell wall of Candida albicans and Saccharomyces cerevisiae by scanning electron microscopy. Can J Microbiol 26, 965-970.

Lee, K., Buckley, H. R. \& Campbell, C. C. (1975). An amino acid liquid synthetic medium for the development of mycelial and yeast forms of Candida albicans. Sabouraudia 13, 148-153.

Marcilla, A., Elorza, M. V., Mormeneo, S., Rico, H. \& Sentandreu, R. (1991). Candida albicans mycelial wall structure: supramolecular complexes released by Zymolyase, chitinase and $\beta$-mercaptoethanol. Arcb Microbiol 155, 312-319.

Marcilla, A., Mormeneo, S., Elorza, M. V., Manclús, J. J. \& Sentandreu, R. (1993). Wall formation by Candida albicans yeast cells: synthesis, secretion and incorporation of two types of mannoproteins. J Gen Microbiol 139, 2985-2993.

Meaden, P., Hill, K., Wagner, J., Slipetz, D., Sommer, S. S. \& Bussey, H. (1990). The yeast KRE5 gene encodes a probable endoplasmic reticular protein required for $\beta-1,6-\mathrm{D}$-glucan synthesis and normal cell growth. Mol Cell Biol 10, 3013-3019.

Mormeneo, S., Marcilla, A., Iranzo, M. \& Sentandreu, R. (1994). Structural mannoproteins released by $\beta$-elimination from Candida albicans cell walls. FEMS Lett 123, 131-136.

Murgui, A., Elorza, M. V. \& Sentandreu, R. (1986). Tunicamycin and papulacandin $B$ inhibit incorporation of specific mannoproteins into the wall of Candida albicans regenerating protoplasts. Biochim Biophys Acta 841, 215-222.

Notario, V. (1982). $\beta$-Glucanases from Candida albicans: purification, characterization and the nature of their attachment to cell wall components. J Gen Microbiol 128, 747-759.

Odds, F. C. (1988). Candida and Candidosis. London: Ballière Tindall. London.

Ponton, J. \& Jones, J. M. (1986). Analysis of cell wall extracts of Candida albicans by sodium dodecyl sulphate-polyacrylamide gel electrophoresis and Western blot techniques. Infect Immun 53, 565-572.

Roemer, T., Delaney, S. \& Bussey, H. (1993). SKN1 and KRE6 define a pair of functional homologues encoding putative membrane proteins involved in $\beta$-glucan synthesis. Mol Cell Biol 13, 4039-4048.

Sanjuán, R., Zueco, J., Stock, R., Font de Mora, J. \& Sentandreu, R. (1995). Identification of glucan-mannoprotein complexes in the cell wall of Candida albicans using a monoclonal antibody that reacts with a (1,6)- $\beta$-glucan epitope. Microbiology 141, 1545-1551.

Sentandreu, R., Mormeneo, S. \& Ruiz-Herrera, J. (1994). Biogenesis of the fungal cell wall. In The Mycota. I. Growth, Differentiation and Sexuality, pp. 111-124. Edited by J. G. H. Wessels \& F. Meinhardt. Berlin, Heidelberg: Springer-Verlag.

Shepherd, M. G. \& Gopal, P. K. (1993). Dimorpbic Fungi in Biology and Medicine, pp. 153-168. Edited by $\mathrm{H}$. Vanden Bossche, F. C. Odds \& D. Kerridge. New York \& London: Plenum Press.

Sullivan, P. A., Chiew, Y. Y., Molloy, C., Templeton, M. D. \& Shepherd, M. G. (1983). An analysis of the metabolism and cell wall composition of Candida albicans during germ-tube formation. Can J Microbiol 29, 1514-1525.

Traxler, P., Fritz, H., Fuhrer, H. \& Richter, W. J. (1980). Papulacandins, a new family of antibiotics with antifungal activity. Structures of papulacandins A, B, C and D. J Antibiot 33, 967-978.

Voller, A. \& Bidwell, D. (1986). Enzyme-linked immunoadsorbent assay. In Manual of Clinical Laboratory Immunology, pp. 359-371. Edited by M. R. Rose, H. Friedman \& J. L. Faehey. Washington, DC: American Society for Microbiology.

Zlotnik, H., Fernandez, M. P., Bowers, B. \& Cabib, E. (1984). S. cerevisiae mannoproteins form an external cell wall layer that determines wall porosity. J Biomol NMR 3, 1018-1026.

Received 16 January 1996; revised 20 March 1996; accepted 26 March 1996. 